\title{
Alternate Assessments to Support Formative Evaluations in an Asynchronous Online Computer Engineering Graduate Course
}

\section{Ms. Ritushree Chatterjee, Iowa State University}

Ritushree Chatterjee is an Instructional Development Specialist working at Engineering-LAS Online Learning at Iowa State University. She did her undergraduate in Chemistry from Delhi University, India and subsequently received her MS in Environmental Chemistry from Iowa State University. She received her second MS in Education with specialization in Curriculum and Instructional Technology and her Instructional Design certificate from Iowa State University in 2015. As an instructional designer, she assists faculty in the College of Engineering and Liberal Arts and Sciences, to design and develop asynchronous online and blended courses, providing technical, pedagogical support and instructional support. She has supported over 25 faculty members successfully transition to the online learning environment and has supported over 50 online courses.

\section{Prof. Ahmed E. Kamal, Iowa State University}

Ahmed E. Kamal received a B.Sc. (distinction with honors) and an M.Sc. both from Cairo University, Egypt, and an M.A.Sc. and a Ph.D. both from the University of Toronto, Canada, all in Electrical Engineering in 1978, 1980, 1982 and 1986, respectively. He is currently a professor of Electrical and Computer Engineering at Iowa State University. Kamal's research interests include wireless sensor networks, cognitive radio networks, optical networks and performance evaluation. He is a Fellow of the IEEE and a senior member of the Association of Computing Machinery. He is an IEEE Communications Society Distinguished Lecturer for 2013 and 2014. He received the best paper award of the IEEE Globecom 2008 Symposium on Ad Hoc and Sensors Networks Symposium, and the best paper award for papers published in Computers and Control in IEE journals in 1993. Kamal serves on the editorial boards of the IEEE Communications Surveys and Tutorials, the Elsevier Computer Networks (COMNET) journal and the Elsevier Optical Switching and Networking journal. He was named the COMNET Editor of the Year in 2008. Kamal was the chair or co-chair of the Technical Program Committees of a number of conferences including the Optical Networks and Systems Symposia of the IEEE Globecom 2007 and the IEEE Globecom 2010, and the Cognitive Radios and Networks Symposium of the IEEE Globecom 2012 conference. He will also serve as the co-chair of the IEEE Globecom 2014 Cognitive Radios and Networks Symposium. He also served as the chair of the Computer Systems section in the Computer Science Grants Evaluation group of the Natural Science and Engineering Research Council of Canada. He is currently the secretary of the IEEE Communications Society Technical Committee on Transmission, Access and Optical Systems.

\section{Dr. Zhengdao Wang, Iowa State University}

Zhengdao Wang received his B.S. degree in Electronic Engineering and Information Science from the University of Science and Technology of China (USTC), 1996, the M.Sc. degree in Electrical and Computer Engineering from the University of Virginia, 1999, and Ph.D. in Electrical and Computer Engineering from the University of Minnesota, 2002. He is now with the Department of Electrical and Computer Engineering at the Iowa State University. His interests are in the areas of signal processing, communications, and information theory. He served as an associate editor for IEEE Transactions on Vehicular Technology from April 2004 to April 2006, an Associate Editor for IEEE Signal Processing Letters between August 2005 and August 2008, and an Associate Editor for IEEE Transactions on Signal Processing between 2013 and 2015. He was a co-recipient of the IEEE Signal Processing Magazine Best Paper Award in 2003 and the IEEE Communications Society Marconi Paper Prize Award in 2004, and the EURASIP Journal on Advances in Signal Processing Best Paper Award, in 2009. He is serving as an Editor for The IEEE Signal Processing Society Online Video Library, and an Associate Editor for IEEE Transactions on Wireless Communications. 


\title{
Alternate assessments to support formative evaluations in an asynchronous online computer engineering graduate course
}

\begin{abstract}
This exploratory essay describes the design and implementation of alternate assessment techniques, such as asynchronous online discussions, virtual labs, open ended module assignments and final project, in an asynchronous online computer engineering graduate course on cognitive radio networks. The course is designed based on the premise of formative evaluations, that is, incorporating a feedback mechanism for each assessment submission. Such feedback provides means for both the instructors and learners to engage with the content and with each other in a meaningful way to create an enriching learning experience. Moreover, designing assessments that stretches students' thought-process is critical to engineering pedagogy. This is implemented in the course as structured threaded discussion forums, governed by instructors that provide thought-provoking guiding questions followed by peer discussion. This essay also explores the design and implementation of virtual laboratory sessions complementing the bi-weekly homework assignments and a final project. It describes the assessment design decisions, based on the overall course learning outcomes, taken to suit the online learners. The aim of this essay is to inform, the community of asynchronous online computer engineering educators, of assessment techniques, other than the traditional formats of multiple choice questions and sit-in proctored exams, based on this cognitive radio networks class. It will also showcase the ways to implement such assessments successfully in an online environment along with the highlighting the overall design process of the course.
\end{abstract}

\section{Introduction}

Online learning is fast occupying the non-traditional educational space. These online learning environments have presented new paradigms, technologies and strategies to the learning sector in engaging students and enhancing student learning. The portion of students in higher education taking at least one online course showed the greatest increase at $7.2 \%$ at four-year public institutions ${ }^{[1]}$. In a literature review on online education undertaken by Larreamendy-Joerns and Leinhardt ${ }^{[2]}$, the authors stated "observed two complementary movements in the educational landscape: the merging of online teaching and learning into the stream of everyday practices at universities, and the increasingly salient role of distance programs in institutions of higher education" (p.572). Online learning environments provide students with continued learning opportunities as well as the flexibility of anytime-anywhere learning. As, such non-traditional learning environments gain popularity; it also calls for non-traditional effective assessment techniques, based on course learning outcomes, with more focus on critical thinking and creativity. It also calls for innovative teaching strategies and course designs, to suit the needs of the online learners.

Assessments play a critical role in formal higher education and are one of the core components of effective learning ${ }^{[3]}$. Bransford, Brown and Cocking stated that the processes of teaching and 
learning needed to be assessment-centered that would provide learners with opportunities to showcase their developing abilities and receive appropriate support to enhance their learning ${ }^{[3]}$. Biggs and Tang described the term 'backwash' which describes the influence of assessments on student learning ${ }^{[4]}$. They further stated that assessments defined what and how students learn rather than it being dictated by the curriculum. Furthermore, the alignment of these assessments to the learning outcomes is critical for constructive learning practices ${ }^{[4]}$. Instructors can then address the inadequacies timely by revisiting the learning materials and providing more support and feedback to students. If the learning gaps surface timely, at regular intervals throughout the duration of the course, it provides adequate opportunities for the instructors and the students to address those move forward with a stronger knowledge base.

Reeves ${ }^{[5]}$ stated

"whether separate or integrated, any approach to improving assessment in online learning must seek to reach optimal levels of "alignment." Alignment is evident when the articulation among learning objectives, content, instructional design (especially the tasks in which students will be engaged), instructor expertise, technological affordances, and assessment strategies is as clear as possible" (p.105).

In contemporary pedagogy, it is crucial that learning environments provide learners ample opportunities to actively participate in learning that will mimic real-world professional settings. Literature has shown that formative learning activities that engage learners in a collaborative and reflective manner also reflect current professional practices ${ }^{[6]},{ }^{[7]},{ }^{[8]}$. Formative assessments provide instructors a truer representation of the knowledge and skills gained by the learners by using various techniques throughout the teaching and learning processes ${ }^{[9]}$.

Assessments should also inculcate a culture of heathy dialogues among peers and go beyond assessing the correctness of given answers. Therefore, assessments are not only important means for the instructor to gauge students' learning gaps but also to hone their intellectual and behavioral instincts. This will prepare them to be part of a more productive future workforce. In general, assessments should provide a more meaningful and richer learning experience to learners.

\section{The context}

Traditionally, assessments in higher education fall under the paradigm of measurement where 'exams' are devised to test knowledge retention ${ }^{[5] .}$ These exams typically are either proctored sit-in type format or multiple-choice questions. Moreover, the types of questions are typically closed ended with a specific set of answer. Such question types could restrict innovative thinking and creativity.

In this course, there is a deviation from these traditional approaches. A continuous and a variety of assessment techniques are employed to gauge student learning. These included a threaded asynchronous online discussion, virtual labs, module assignments and a final project. In all of these assessments, the instructors paid special attention to the kind of questions being asked. They gave the students ample opportunities to stretch their imagination, hone their critical thinking abilities, develop negotiating abilities, and devise innovative strategies and ideas. The questions mimicked real world scenarios and exposed students to a more practical side of the content. A critical component of these assessments were the incorporation of a feedback 
mechanism, wherein, they provided meaningful and timely feedback to students on their submissions. Hence, in this essay, this non-traditional approach is deemed as 'alternate assessment'.

The students also participated in two voluntary surveys where they provided feedback on the course design and learning experiences. However, the Institutional Review Board's approval could not be obtained timely, and hence, the survey results could not be part of this essay. The instructors, however, have provided with their perspectives and that anecdotal evidence serves as a strong support to the rhetoric presented here.

Assessments cannot be designed in isolation to other course components such as course structure, learning resources and activities, and interactions. All of these components are intertwined and driven by the overall course outcomes and objectives. In the following sections, the design process of this course will be elucidated showcasing such an integration involving all aspects of the course. The design and implementation of the course assessments will also be described in greater detail. This includes the rationale behind each type of assessment, example questions, and the instructor's insights. This essay also has an instructor's perspective section with reflection on the assessments and the design phases by the instructors.

\section{The course background}

CPR E/ E E 522, Cognitive Network Design, is a new graduate level course in computer engineering and is cross-listed with electrical engineering. The area of telecommunications has been, and continues to be an important area of the engineering discipline. The IEEE Communications Society and the Accreditation Board for Engineering and Technology (ABET) have recently approved criteria for accrediting programs in Telecommunications ${ }^{[10], ~[11], ~[12] ~}$ which is a testimony of its growing importance. The area of telecommunications is unique in the sense that it overlaps both electrical engineering and computer science and engineering, having roots in communications theory, computer networks, algorithms, and several other disciplines. It combines both theory and practice, and students and professionals need training in a crossdisciplinary manner.

This topic is not only of interest to graduate students but also to professionals working in the area of network design, wireless communication, and computer networks. The rationale for offering this course in the online format was to reach out to a broader audience, which included both graduate students and professionals working in network design and related areas.

Due to the multidisciplinary nature of this course, it was, therefore, co-taught by two full professors of a large mid-western university who are experts in computer networks, wireless communication and communication theory. The instructors have had prior experience with distance students in their classes, however, in a 'lecture-capture' format, where their face-to-face lectures were recorded and then broadcasted to the distance students. In that sense, it can be said, that the instructors were novice to asynchronous online teaching and learning.

This course was a recipient of a university grant, specifically meant for developing asynchronous online courses, from a distance-learning sub-unit of the university. Hence, the course was designed in collaboration with an instructional designer with expertise in online learning and 
learning environments. The learners consisted a mix of both graduate students and professionals working in a related area.

\section{Design approach}

This course was designed with the Backward Design approach developed by Grant Wiggins and Jay McTighe ${ }^{[13]}$. The backward design process starts with intended purpose and result of the design challenge in mind. Wiggins and McTighe ${ }^{[13]}$ stated "one starts with the end -the desired results (goals or standards)- and then drives the curriculum from the evidence of learning (performances) called for by the standards and the teaching needed to equip students to perform" (p. 8). It essentially consists of three phases (1) identifying desired results (2) determining acceptable evidence and (3) planning learning experiences and instruction. Moreover, this approach does not alienate assessment from learning rather considers it to be part of the learning process. Hence, the faculty thinks about the resources and experiences along with ways to assess student learning.

The instructors therefore started the design process with laying down the learning outcomes of the course. The course was divided into eight learning modules and each module had specific module-level learning objectives. These objectives and outcomes were written using the different levels of desired learning as stated in Bloom's taxonomy ${ }^{[14]}$. The following section illustrates these outcomes and objectives were and how each objective was tied to the learning outcome. It also shows which assessments would assess each learning outcome.

The overall course learning outcomes were as below:

1. (Analyze) Analyze the problems motivating cognitive radio networks, and how cognitive radio networks overcome these problems.

2. (Understand) Explain physical layer aspects of cognitive radio networks.

3. (Understand) Explain the different components of a cognitive radio, and how they interwork.

4. (Understand) Explain how spectrum sensing and spectrum decision are performed in cognitive radio networks.

5. (Analyze) Analyze the performance of spectrum sensing strategies.

6. (Understand/Analyze/Apply) Illustrate spectrum sharing and resource allocation. strategies in cognitive radio networks, and be able to design and analyze such strategies.

7. (Evaluate) Evaluate issues affecting operation at layers 2 and 3 in cognitive radio networks, and the protocols developed for these layers.

8. (Understand) Outline standards developed for cognitive radio networks, and application domains and environments of those standards.

\section{Module -wise learning objectives and their alignment to overall course outcomes}

1. Introduction:

- Understand the problems of spectrum exhaustion and spectrum under-utilization (tied to learning outcome\#1)

- Understand the basic ideas behind cognitive radio networks (CRNs), and how CRNs overcome the above problems. (tied to learning outcome\#1) 
2. Cognitive Radio Networks Architecture

- Understand the CRN architecture and the functions of the different layers in the architecture (tied to learning outcome\# 2 and 3 )

- Understand and analyze the cognitive radio node architecture and the different modules of the cognitive radio (tied to learning outcome\# 2 and 3)

3. Software Defined Radio Architecture

- Understand the architecture and principles of software defined radios (SDRs) (tied to learning outcome\# 3)

- Be able to program and use SDRs in CRNs (tied to learning outcome\#3)

4. Spectrum Sensing

- Learn and understand the different metrics and techniques of spectrum sensing (tied to learning outcome\# 4)

- Learn the theory behind sensing using energy detection and sensing using feature detection (tied to learning outcome\# 4)

- Understand cooperative spectrum sensing (tied to learning outcome\#4)

- Analyze the performance of different sensing techniques (tied to learning outcome\#5)

5. Spectrum Decision

- Learn spectrum modeling and characterization techniques (tied to learning outcome\# 4)

- Study, understand and analyze decision strategies for spectrum selection and reconfiguration (tied to learning outcome\#4)

- Develop optimization models for spectrum decision (tied to learning outcome\#4 and 5)

6. Spectrum Sharing

- Study and understand resource allocation optimization strategies in CRNs (tied to learning outcome\# 6)

- Learn game theory and its application in spectrum sharing and be able to apply game theory in spectrum sharing strategies (tied to learning outcome\#6)

- Learn the different device tuning strategies and analyze their complexity and performance (tied to learning outcome\# 2 and 6)

7. Spectrum Mobility

- Learn and understand the spectrum monitoring function in CRNs, and be able to analyze their performance (tied to learning outcome\# 2 and 7)

- Learn and analyze spectrum handoff approaches (tied to learning outcome\# 2,6 and 7)

- Learn and analyze connection management protocols in CRNs (tied to learning outcome\# 6 and 7)

8. Standards and Applications

- Study and understand the different CRN standards and their application environments (tied to learning outcome\#8)

- Learn some of the important applications of CRNs (tied to learning outcome\# 8)

- Be able to apply CRN concepts to solve problems of bandwidth scarcity (tied to learning outcome\# 1-8) 
During this process, the assessments were also devised aligning these to the overall course outcomes and module level objectives.

Learning outcome 1: Was assessed by: asynchronous online discussions and final project Learning outcome 2: Was assessed by: homework

Learning outcome 3: Was assessed by: project and lab

Learning outcome 4: Was assessed by: homework and lab

Learning outcome 5: Was assessed by: homework and lab

Learning outcome 6: Was assessed by: homework and lab

Learning outcome 7: Was assessed by: final project and class discussions

The learning resources, mainly consisting of lecture videos and readings, were also created keeping in mind the objectives it intended to achieve. The objectives were also stated in these videos explicitly at the beginning and end of each video.

Litzinger, Lattuca, Hadgraft, and Newstetter ${ }^{[15]}$ have recognized the significance of aligning learning objectives, learning experiences and assessments and consider this as one of the steps instrumental in transforming engineering education. This approach helped the instructors to refine and revisit the indented goals of each module, the quantum of learning materials required and the necessity of the various assessments in the course.

\section{Course structure}

The course was divided into eight learning modules relevant to the area of interest and keeping in mind the needs of the industry. Each module was further divided into several subtopics. The main learning resources were short, pre-recorded, lecture videos and lectures notes created and annotated by the instructors. There were additional materials in the form of textbook readings and other supplemental videos. The course schedule was designed while keeping in mind the needs of the online learner. The assessment submissions were paced out to avoid any overlaps of due dates. Weekends were included in the submission time frame. This gave sufficient time to professionals taking the course, who may otherwise be occupied by other commitments on weekdays. Each module was available to students sequentially based on the course schedule. This was specifically chosen to scaffold student learning as materials covered in one module served as a prerequisite knowledge for the content of the following learning module.

\section{Interactions}

There were multiple ways through which interaction between learners and instructors was facilitated in the course using the online learning management system (LMS), Blackboard Learn. Instructors used the Announcement tool to send out regular updates about the course to the students, which included information about upcoming tasks and deliverables.

There was an 'Introduction' forum where students introduced themselves to the class. This provided them the opportunity to familiarize themselves with their fellow classmates and connect among themselves and with the instructors. The instructors also posted their respective introductions, which served as a sample post for the students, if anyone needed one. 
There was a discussion board set up called the 'Help Forum', where students could post any questions or comments they had regarding the course. The instructors moderated this forum but peers were encouraged to respond to queries. The learners extensively used this forum and there were around 190 discussion posts. This threaded discussion forum acted as a support system for the students where they could find strategies to the issues and comments posted. Additionally, there were the graded threaded module discussions, which provided for a more focused content driven discussions among peers. Feedback was also provided on all assessments, which gave learners another venue for interacting with the instructors and peers.

\section{Online delivery platform}

The platform for online delivery was Blackboard Learn. This is the learning management system widely supported by the university. The navigation was sectioned into four broad categories, namely, Start Here, Course Content, Quicklinks and Getting Help. The 'Start Here' section consisted of a module with all necessary information to help the online learner get oriented with the course page as well as the course. It included information on the faculty, course navigation, syllabus, schedule, technical assistance, information on student support and services on campus as well as special accommodation resources. The 'course content' section is where the main course learning modules were housed along with all the assessments. The Quicklinks provided for a faster access to learning resources and Getting Help provided students multiple outlets to reach out if any assistance with the course or otherwise was needed.

\section{Assessments}

In this cognitive radio networks course, the instructors consciously chose to keep away from the typically traditional forms of assessments such as automated multiple-choice questions or proctored sit-in exams. The reason behind this decision is the nature of this course being a research-oriented course, and a design problem may be solved using a multiplicity of approaches. Hence, various types of alternate assessment techniques, intercepted with feedback from instructors, were adopted to enhance student learning in tune with the needs of the subject matter.

These assessments were spread throughout the semester and acted as checkpoints for learners as well as instructors to assess their respective learning and teaching strategies. It gave both parties opportunities to revisit, re-iterate and address the roadblocks in the learning cycle and provided for a more meaningful learning experience.

Module discussions: At the completion of each learning module, students engaged in asynchronous online discussions with their peers. The question posed by the instructor served as a starting point to initiate the conversation. The discussions were graded and moderated by the instructors. Learners were also provided with a grading rubric so that they could assess what constituted an acceptable response and netiquettes. Learners were given a week's time to respond and engage in discussions. 
There was no minimum requirement of the number of posts students could make. However, it was observed that learners were deeply motivated to contribute to these discussions and surpassed the expectation set by the rubric. On an average, there were 37 discussions posts for each of the seven module discussion forums. Not only did they respond to the posed question but also engaged in co-learning, where they offered explanations to fellow classmates on certain misconceptions. Instructors and students both subscribed to these forums and received email notification whenever a post was made.

These module discussions provided an excellent 'peer-learning' and 'interactive-learning' opportunity for learners. It also surfaced misconceptions that were addressed by the instructors. Peers also responded to queries and also provided explanations to such misconceptions.

This atypical assessment was in tune with the shifting paradigms in engineering education wherein research in the fields of educational, learning and social-behavioral sciences are being applied to engineering courses ${ }^{[16]}$. Literature has shown the benefits of peer interaction and learning. Such activities developed stronger higher order thinking capabilities in student and reduced their feelings of isolation in an online environment ${ }^{[17], ~[18]}$. Vonderwell, Liang, and Alderman ${ }^{[8]}$ studied asynchronous online discussions in five master's level graduate courses, where they were used as means of peer and self-formative assessment. The authors observed that such a strategy provided opportunities to learners and instructors to engage in social interactions, which provided for ongoing assessment of student learning.

Moreover, this approach was a novel one, as online asynchronous discussions, are not a foremost choice of instructors, when it comes to assessments, especially in engineering courses, which typically are considered as 'hard applied' courses ${ }^{[19]}$.

\section{Instructor's insight:}

This assessment technique provided novel insights into the posed problem and different perspectives on the same. We think the discussion forums, and questions were useful in getting the off-campus students to engage, especially that they were responding to each other. An important factor that contributed to this was that several of the online students were telecommunications professionals and their contributions were representative of their industrial experience, hence nicely complementing one another. Such kind of formative assessment techniques provides meaningful learning experience to learners by means of timely and effective feedback mechanisms.

Example of discussion questions:

- Comment on the optimality/advantages of using bits as the common interface between various sources and the communication system.

- Feynman's restaurant problem can be stated as follows: http://www.feynmanlectures.info/exercises/Feynmans_restaurant_problem.html Assume that a restaurant has $N$ dishes on its menu that are rated from worst to best, 1 to $N$ (according to your personal preferences). You, however, don't know the ratings of the dishes, and when you try a new dish, all you learn is whether it is the best (highest rated) dish you have tried so far, or not. Each time you eat a meal at the restaurant you either 
order a new dish or you order the best dish you have tried so far. Your goal is to maximize the average total ratings of the dishes you eat in $M$ meals (where $M$ is less than or equal to $N$ ).

If we have $N$ frequency band to explore, and after sensing $M$ bands, we decide to use the best band to transmit for the rest of the time-slot. Is this problem the same as Feynman's restaurant problem? If not, what are the differences.

- Four approaches for handoff were introduced: 1) no handoff, 2) reactive, 3) proactive, and 4) the hybrid approach. Consider each of these approaches and explain which applications, or which environments these can be used in.

Module Assignment: After the completion of each module, learners were expected to submit an assignment to assess as well as enhance their understanding of the conceptual knowledge. Submissions were through Blackboard within a timeline of two weeks. A detailed rubric was provided to students where the criteria for acceptable responses were detailed. There were no instances during the course of the semester when the rubric had to be altered.

The problems were 'multi-faceted' ${ }^{[17]}$ and mimicked more real-life situations that students might encounter when pursuing their professional endeavors rather than a set algorithmic type approaches to problem solving. Multifaceted problems were described by Ogilvie ${ }^{[17]}$ problems as problems that "lie somewhere between well-structured problems found in textbooks and large, ill-defined, open-ended challenges in the degree-of-difficulty these pose to students" (p. 3).

Instructors provided feedback on these assignments and worked together with the learners to form a sound understanding of the concepts.

\section{Instructor's insight}

Several of the problems included modification and extensions of systems and algorithms covered in class such that the new designs will be more suited to other environments, or to serve different types of applications. These problems had no specific model answer, and as such, it gave the students a chance to be creative. Solving such problems would deepen learners' understanding of the concepts and analytical skills and better equip them to navigate situations in their chosen career path.

Examples of problems:

- In the course, the optimal mixed non-cooperative game strategy was introduced. Verify its optimality. In the formulation of the Centralized Optimal Spectrum Allocation problem, it was assumed that interference between SUs is independent of the channel. We would like to extend this model and redefine the channel interference constraint as 3-D matrix, with elements $c(m, n, k)$, which is equal to 1 if and only if SUs $n$ and $k$ interfere on channel $m$. Revise the ILP to take the modified channel interference constraints into account.

- In Module $6 b$ Part 2, several modes of operation were introduced, and the receiverbased spectrum allocation (RBA) was treated in detail using an optimization formulation. In the reference paper, and in Figures 10-13, it is shown that the receiverbased allocation always outperforms the All Tunable Allocation (ATA) and the Transmitter-Based Allocation (TBA) in terms of the number of served MCs. In this 
problem, you are required to provide a careful and detailed explanation for why RBA outperforms both TBA and ATA. You need to take into account all factors affecting the "average number of served MCs" metric.

- We would like to use the reactive handoff strategy with the multiband CRN handoff approach. For simplicity, assume that the SU uses 2 bands, and it applies the reactive handoff approach to each of the two channels independently. The rest of the assumptions are the same as in the notes. Comparing the duplexing (sharing the resources between access point and user terminals) mechanism of 802.11 and 802.22, what is/are the main difference(s)? i. Derive the expression for pm under this scenario. ii. Find the mean $S U$ session time in this case.

Laboratory experiments: One of the key assessments of this course were the virtual laboratory experiments spread throughout the semester. There were three such experiments based on simulation of some real life application of the concepts being covered in the course. They were developed using USRP software defined Radios (SDRs) that the instructors had access to. Each student was asked to sign up for a time slot. They could sign up for up to two-time slots of two hours each including on weekends. This schedule was shared with the entire class to avoid duplication. Instructions were provided to connect to the university's virtual private network and ways to launch remote desktop function to connect to the servers from their personal computers. Teaching assistant was available to help the students via email and through video conferencing. After completion of the experiments, learners were expected to write a lab report within a week. A detailed specification of the format of the report was also provided to the students.

The first lab was introduction to LabVIEW, which is a system design platform and development environment for a visual programming language from National Instruments (NI). USRP can be easily configured using LabVIEW software. The objectives of the first lab can be summarized as follows; (i) Become familiar with LabView and how to create a Virtual Instrument (VI). (ii) Become familiar with structures in LabView e.g., While Loops, For Loops, Case Structures, etc. (iii) Become familiar with representing the results in many way e.g., scales, indicators, graphs, etc. The objectives of the second lab can be summarized as follows: (i) Become familiar with USRP and its specifications. (ii) Become familiar with some practical implementations using USRP, such as build FM receiver (FM demodulation).

Finally, the last lab focuses on cognitive radio concepts and the objective of this lab can be summarized as follows: (i) Learn how to build spectrum monitoring systems using NI USRP hardware and LabView software.

(ii) have an idea on how to implement different cognitive radio schemes/system models using USRPs.

\section{Instructor's insight}

The other assessment method used in this course was the online labs. Most graduate courses in our department do not have a lab component. The decision of adding a lab component to this course was to make sure that students would be able to apply the theory they learn in class using real equipment. Since the lab equipment were accessed online, there were some limitations, and all operations had to be done under the control of software. Therefore, students were assessed on how they were able to make the lab work without physical contact with lab equipment. There 
were limitations, and in particular the limited number of SDRs, which prevented us from offering labs that implement large scale networks with SDRs communicating with each other.

Final Project: Learners were expected to select a topic from a given list or from an area of interest of their choice related to network design. Upon approval of their proposal, by the instructors, learners made a presentation on their chosen topic. The presentation was in an audiovideo format that was uploaded to the LMS. This project was the culminating assessment of this course where learners proposed a tangible solution to their chosen problem by applying the knowledge learnt throughout the course. Instructors would provide feedback and upon refinement of their project presentation, students would then submit a written report. A detailed rubric and expectations was conveyed to the students at the beginning of the course.

The final project could be one of three types: 1) a survey of a topic related to the course, but was not covered in enough depth, or not covered at all. Students would typically after surveying relevant approaches and techniques, would provide an in-depth critique and comparison of those techniques; 2) a performance study, which might be based on simulation or analytical modeling, of one or two relevant techniques which were covered in class. A performance comparison of such techniques may also be included; or 3) a proposal for new algorithm or system that is relevant to the course and its coverage. Also, some modeling or analysis of the proposal is expected. The projects proposed and submitted spanned all three types.

\section{Instructor's insight}

The purpose of the final project was to impart specialized knowledge in students. Students writing a project in a certain area would typically gain more expertise in this area compared to the rest of the class. It also provided the students a chance to explore new directions of research and developments related to cognitive radio networks. The presentations were used for two purposes: 1) to disseminate further knowledge to the entire class, and 2) to assist the assessment process by giving the instructors a chance to further probe the students' knowledge and the gained experience in the area of the project. In general, it added an element of diversity that the entire class benefited from.

Examples of projects selected by students:

- Energy efficient spectrum management strategies in CRNs

- Cooperative spectrum sensing strategies in CRNs

- $\quad C R N s^{\prime}$ security vulnerabilities and solutions

- CRNs' applications

- Game theoretic spectrum sharing approaches in CRNS

\section{Instructor's Perspective on assessments and overall course design}

The course addresses an important area in wireless communications. Although there are several students in our department working in this area, there was no formal course in this area. Therefore, this course fills a void. The area of the course is broad, and there are many techniques and protocols that have been developed. We only had to cover a few examples, and left it to those interested to explore the rest on their own. We did not use a book, but research 
papers. We are in the process of co-authoring a book in this area, and plan to use drafts of some of the chapters of this book in the course in the next offering of the course.

In this course, we experimented with several new tools of knowledge delivery and assessment. Information and knowledge delivery used the asynchronous format, which we had no prior experience with. Our previous online teaching experience was based on the broadcast of recorded face-to-face lectures to the online section of the class. The class was not necessarily designed with the distance students in mind.

This new course was the first fully online asynchronous experience for us that was specifically designed for the online students in collaboration with an instructional designer. This course received a university grant for such a development. It was found that this asynchronous format had both pros and cons. The fact that lectures could be recorded any time, and there was a chance to record and re-record lectures, or parts of the lectures in order to enhance the content or the delivery, was found to be a big advantage of this format. Since the pre-recorded lectures were also presented to on-campus students, the instructors used a hybrid format of playing parts of the pre-recorded lectures, and then pausing to have an in-class discussion. On the negative side, we usually spent long hours recording lectures as they took advantage of the asynchronous format by pursuing lecture improvements. However, this is already mitigated by the fact that the prerecorded lectures will be reused in future offerings of the course.

An exam-less based assessment was also a new experience for us. It was found that the students felt more apt to understanding, and keener on learning the material and the concepts in depth, rather than memorizing them.

Below are some more of our observations regarding the assessments used in this course. The statements written below are based on our assessment of the course and the students, and not based on surveys. The written documents in the course evaluations do not provide any useful information, or any suggestions for improvements. I did ask students at the end of the course if this course, and the material covered have met their expectations, and all of them said yes.

- Homework: used several open-ended problems for which there no specific answer, which gave students a chance to be creative in the approaches they used.

- Discussions: The discussion forums were a new assessment approach that we used in this course. On one hand, they proved very beneficial since the students came from different backgrounds, including professionals who took the course online, and were able to contribute based on their practical experience. And, on the other hand, since the forums were interactive, it allowed students to reflect on their answers while taking into consideration other students' response, and try to revise and perfect their answers. However, initially students were just providing their own perspectives without getting into discussions. However, later on, students got more involved in the discussions and positively contributed to the enhancement and objectivity of the discussions.

- Project: provided diversity and in-depth specialization. The presentations were used as an assessment tool.

- Labs: the purpose of using labs in this course was to complement the theoretical knowledge gained through lectures with a practical experience of tools that are 
commonly used in the CRN context. Since we had a limited number of SDRs, we could only offer a few small-scale lab experiments, and could not have large-scale experiments in which SDRs talked to each other. Our focus in the experiments was to have the students gain experience with the programming of the SDRs, and their use in spectrum sensing in CRNs. Most students carried out the labs as expected. The only problems we had were related to remote accessibility due to machine configurations. In future offerings of this course, we plan to obtain several more SDRs, which would allow us to expand on the lab experiments, e.g., by having students work in teams and program SDRs to form CRNs.

\section{Conclusion}

This essay is an exploratory description of the design of an online asynchronous course in cognitive radio networks with emphasis on the various types of alternate assessments techniques implemented such as asynchronous online discussions, virtual labs, open ended module assignments and a final project. These assessments were 'alternate' in regards to their design and format, where they challenged students' creativity and nurtured their critical thinking. With a multiplicity of assessments, students received a continuous feedback on their learning and adequate and timely support to address any inadequacies. This approach added a layer of novelty to this course and made it a unique experience for the students as well as the instructors, who were novice asynchronous online instructors. The instructors provided their perspective in support of the assessment techniques implemented in this course and the overall design process.

Overall, the course learning outcomes and module objectives guided the design and development of the learning resources, activities and assessments. Alignment of the assessments and learning resources and activities with the learning outcomes was also a critical design component and a highlight of this course.

Best practices of online learning were incorporated throughout the course. These included strategies such as shorter lecture videos, a simple course organization and navigation, a welldefined course schedule and syllabus, an 'about the course' module explaining all essential components of the course. There were provisions for interactions, between peers, and instructors and peers, which were integral to the course.

This essay will inform the community of engineering educators on online course design practices and alternate assessment techniques. This paper provides a useful insight to both novice and experiences online instructors who can benefit from the format and best practices of online learning incorporated in this course. Instructors may find strategies to integrate non-traditional assessment techniques described in this essay. By employing such strategies, educators could make the online learning experience richer and fulfilling both for the learners and for themselves.

\section{Limitation and future work}

This course was a newly developed course in the engineering department of the university with an ever-evolving content. With a research driven content, the instructors primarily focused on providing students a multitude of assessment experience to gain a sound knowledge intertwined 
with practical applications. Providing a wholesome learning experience with appropriate peer and instructor support, timely feedback and response and a seamless LMS experience also remained their priority. However, in this first iteration of the course, the effectiveness of the assessments was not directly evaluated from the students' point of view. Students did partake in two voluntary surveys regarding the user and learning experience, the results of which could not be shared due to lack of timely approval by the institutional review board. The instructors, however, provided their own experiences and observations regarding the assessment techniques and course design. This is shared as an anecdotal evidence in this essay.

Plans for further study includes ameliorating the course assessments and design, in the second offering of the course, based on learners' feedback and instructors' experience. The effectiveness of the course assessments techniques and design will be assessed through beginning- ofsemester, mid-semester, and end-of-semester surveys as well as learner analytics retrieved from the LMS. The existing surveys will be modified to include specific questions on each of the assessments employed in the course. Results will be reported back to the community. This will expand the knowledge base on the use and efficacy of such alternative assessment techniques in asynchronous online learning environments in engineering education. 
Bibliography

[1] I. E. Allen and J. Seaman, "Grade level: Tracking online education in the United States," Babson Survey Research Group., Babson Park, MA, 2015.

[2] J. Larreamendy-Joerns and G. Leinhardt, "Going the distance with online education.," Review of educational research, vol. 76, no. 4, pp. 567-605, 2006.

[3] J. D. Bransford, A. L. Brown and R. R. Cocking, How People Learn: Brain, Mind, Experience, and School, Washington, DC: National Academy Press, 2001.

[4] J. Biggs and C. Tang, eaching for Quality Learning at University, Maidenhead: Open University Press., 2011.

[5] T. C. Reeves, "Alternative assessment approaches for online learning environments in higher education," Journal of Educational Computing Research, vol. 21, no. 1, pp. 101-111, 2000.

[6] J. Mackey, "Virtual learning and real communities: online professional development for teachers," in Effective blended learning practices: evidence-based perspectives in ICT-facilitated education, Information Science Reference, New Zealand, 2009, pp. 163-181.

[7] E. K. Sorensen and E. S. Takle, "Investigating knowledge building dialogues in networked communities of practice. A collaborative learning endeavor across cultures.," Interactive educational multimedia: IEM, vol. 10, no. 1 , pp. 50-60.

[8] S. Vonderwell, X. Liang and K. Alderman, "Asynchronous discussions and assessment in online learning," Journal of Research on Technology in Education, vol. 39, no. 3, pp. 309-328, 2007.

[9] S. K. Vonderwell and M. Boboc, "Promoting formative assessment in online teaching and learning," TechTrends, vol. 57, no. 4, pp. 22-27, 2013.

[10] I. F. Akyildiz, W. Y. Lee, M. C. Vuran and S. Mohanty, "NeXt generation/dynamic spectrum access/cognitive radio wireless networks: A survey," Computer Networks, vol. 50, no. 13, pp. 2127-2159, 2006.

[11] IEEE Communications Society Breaking News , "Telecommunication Engineering Now Has Official Accreditation Criteria," 30 March 2014. [Online]. Available: http://www.comsoc.org/blog/breakingnewstelecommunication-engineering-now-official-accreditation-criteria. [Accessed 30 January 2016].

[12] K. Pretz, "Telecommunications Engineering Is Now a Distinct Education Discipline," 21 November 2014. [Online]. Available: http://theinstitute.ieee.org/career-and-education/university-education/telecommunicationsengineering-is-now-a-distinct-education-discipline.

[13] G. P. Wiggins and J. McTighe, "What is backward design?," in Understanding by design, NJ, Merill Prentice Hall, 2001, pp. 7-19.

[14] L. W. Anderson and D. R. Krathwohl, A taxonomy for learning, teaching, and assessing: A revision of Bloom's taxonomy of educational objectives., New York: Longman, 2001.

[15] T. Litzinger, L. R. Lattuca, R. Hadgraft and W. Newstetter, "Engineering education and the development of expertise," Journal of Engineering Education-Washington, vol. 100, no. 1, pp. 123-150, 2011.

[16] J. E. Froyd, P. C. Wankat and K. A. Smith, "Five major shifts in 100 years of engineering education.," Proceedings of the IEEE, 100(Special Centennial Issue), vol. 100, no. Special Centennial Issue, pp. 1344-1360, 2012.

[17] C. A. Ogilvie, "Changes in students' problem-solving strategies in a course that includes context-rich, multifaceted problems.," Physical Review Special Topics-Physics Education Research, vol. 5, no. 2, p. 020102, 2009.

[18] T. Litzinger, L. R. Lattuca, R. Hadgraft and W. Newstetter, "Engineering education and the development of expertise," Journal of Engineering Education-Washington, vol. 100, no. 1, p. 123, 2011.

[19] R. Beebe, S. Vonderwell and M. Boboc, "Emerging Patterns in Transferring Assessment Practices from F2f to Online Environments," Electronic Journal of e-Learning, vol. 8, no. 1, pp. 1-12, 2010.

[20] S. R. Gikandi, D. Morrow and N. E. Davis, "Online formative assessment in higher education: A review of the literature," Computers \& Education, vol. 57, no. 4, pp. 2333-2351, 2011. 
